This is the author's final, peer-reviewed manuscript as accepted for publication. The publisher-formatted version may be available through the publisher's web site or your institution's library.

\title{
Identification in models of gasoline pricing
}

Lance Bachmeier

\section{How to cite this manuscript}

If you make reference to this version of the manuscript, use the following information:

Bachmeier, L. (2013). Identification in models of gasoline pricing. Retrieved from http://krex.ksu.edu

\section{Published Version Information}

Citation: Bachmeier, L. (2013). Identification in models of gasoline pricing. Economics Letters, 120(1), 71-73.

Copyright: () 2013 Elsevier B.V.

Digital Object Identifier (DOI): doi:10.1016/j.econlet.2013.03.029

Publisher's Link: http://www.sciencedirect.com/science/article/pii/S0165176513001389

This item was retrieved from the K-State Research Exchange (K-REx), the institutional repository of Kansas State University. K-REx is available at http://krex.ksu.edu 


\title{
Identification in Models of Gasoline Pricing
}

\begin{abstract}
This paper presents evidence that the price of oil does not respond contemporaneously to shocks to the US gasoline market. We find no support for the hypothesis of feedback from the US gasoline market to the price of oil, justifying the identification of impulse response functions by applying a Choleski decomposition (see, e.g., Kilian (2010)). Our results have implications for tests of asymmetric gasoline price responses and forecasting models of the price of crude oil.
\end{abstract}

\section{Introduction}

The relationship between oil prices and retail gasoline prices has been the subject of much research. An important application has been the "rockets and feathers" literature that has tested for different responses of retail gasoline prices following oil price increases and decreases. ${ }^{1}$ Following the early work of Borenstein, Cameron and Gilbert (1997), it is common to model this relationship using a variant of an error correction model such as

$$
\Delta \operatorname{gas}_{t}=\alpha+\sum_{i=1}^{k} \gamma_{i} \Delta \operatorname{gas}_{t-i}+\sum_{i=0}^{k} \beta_{i} \Delta o i l_{t-i}+\theta z_{t-1}+\varepsilon_{t} .
$$

where gas $_{t}$ is the price of gasoline in period $t$, oil $_{t}$ is the price of oil in period $t$, and $z_{t-1}$ is the deviation from a cointegrating relationship between the two variables. Equation (1) can be generalized to allow for asymmetry by allowing the $\beta$ coefficients to be different for positive and negative values of $\Delta$ oil (see Kilian and Vigfusson (2011)).

As emphasized by Geweke (2004), in spite of the complications caused by feedback from the price of gasoline to the price of oil, most of the literature has treated the price of oil as exogenous. He suggests three tools that can be used to investigate the possibility of feedback: simultaneous equations methods that rely on exclusion restrictions; restrictions on the dynamics, as in the macroeconomics vector autoregression literature; and feedback decomposition.

This paper uses the heteroskedasticity-based estimator introduced by Rigobon (2003) to estimate a model that allows both the price of gasoline and the price of oil to be endogenous. Once we have the estimates of our model, it is straightforward to test for feedback. We find no evidence against the null hypothesis of no feedback from gasoline prices to crude oil prices.

\footnotetext{
${ }^{1}$ See e.g. Godby, et al (2000), Bachmeier and Griffin (2003), and Verlinda (2008).
} 
In addition to the rockets and feathers literature, feedback from the price of gasoline to the price of crude oil matters for oil price forecasting models. See Alquist, Kilian, and Vigfusson (2012) for a review of the literature on oil price forecasting. Shocks to the demand for crude oil have driven oil price fluctuations in recent years (see Kilian (2009), Hamilton (2009), and Kilian and Murphy (2012, 2013) for evidence and discussion). In this paper, we ask whether variation in US gasoline prices has a contemporaneous effect on the price of crude oil. For example, one may expect higher demand for US gasoline to be reflected not only in higher prices at the pump, but also in higher oil prices. Our results suggest that this feedback is negligible in the short run, making it appropriate to treat contemporaneous movements in the price of gasoline as a response to crude oil price changes.

\section{Model and Identification}

Our baseline model is a vector error correction (VEC) model of gasoline and oil prices:

$$
\begin{aligned}
\Delta \text { gas }_{t} & =\alpha_{g}+\sum_{i=1}^{k} \gamma_{i} \Delta g a s_{t-i}+\sum_{i=0}^{k} \beta_{i} \Delta o i l_{t-i}+\theta_{g} z_{t-1}+\varepsilon_{g t} \\
\Delta o i l_{t} & =\alpha_{o}+\sum_{i=0}^{k} \delta_{i} \Delta g a s_{t-i}+\sum_{i=1}^{k} \omega_{i} \Delta o i l_{t-i}+\theta_{o} z_{t-1}+\varepsilon_{o t}
\end{aligned}
$$

where $\varepsilon_{g t}$ and $\varepsilon_{o t}$ are uncorrelated structural shocks to the gasoline and oil markets, respectively. The oil and gasoline price data were downloaded from the Energy Information Agency website. The data are daily frequency covering the period June 2, 1986 to June 5, 2012. gas is the natural logarithm of the New York Harbor Conventional Gasoline Regular Spot Price FOB. oil is the natural logarithm of the Cushing, OK WTI Spot Price FOB. The lag length was chosen by minimizing the SIC for the reported results, but we have done all of the analysis with the lag length selected by minimizing the AIC, and it had little effect either qualitatively or quantitatively. The error correction relationship estimated using the Johansen method is

$$
z_{t}=\text { gas }_{t}-1.13 \text { oil }_{t}
$$

We also report results for a VAR model in levels ${ }^{2}$ and a VAR model in differences.

The presence of time $t$ variables as regressors in the system (2) - (3) means there is an identification problem. One way to achieve identification would be to assume $\delta_{0}=0$. That would be the equivalent of identifying the impulse response functions by a Choleski decomposition on the reduced form residual

\footnotetext{
${ }^{2}$ The VAR model in levels is more robust, as it is consistent with the variables being stationary, nonstationary and cointegrated, or nonstationary and not cointegrated, but it is inefficient if there is a unit root. Our focus is on the vector error correction model, because that is the model most commonly estimated in the existing literature.
} 
covariance matrix. While timing restrictions are common in the macroeconomic literature (Kilian and Vega (2011)), imposing the assumption $\delta_{0}=0$ is hard to justify a priori. Geweke (2004) discusses other possible solutions. ${ }^{3}$

Rigobon (2003) showed how heteroskedasticity in the structural shocks can be used to identify (2) - (3). Consider the restricted system

$$
\begin{aligned}
\Delta \text { gas }_{t} & =\beta_{0} \text { oil }_{t}+\varepsilon_{g t} \\
\Delta \text { oil }_{t} & =\delta_{0} \text { gas }_{t}+\varepsilon_{o t} .
\end{aligned}
$$

Letting $\widehat{\beta}_{0}$ be the OLS estimate of $\beta_{0}$, it can be shown (see e.g. Hamilton (1994, pp. 233-4)) that

$$
\operatorname{plim} \widehat{\beta}_{0}=\frac{\delta_{0} \sigma_{g}^{2}+\beta_{0} \sigma_{o}^{2}}{\sigma_{g}^{2}+\sigma_{o}^{2}}
$$

where $\sigma_{g}^{2}=\operatorname{var}\left(\varepsilon_{g}\right)$ and $\sigma_{o}^{2}=\operatorname{var}\left(\varepsilon_{o}\right)$. The OLS estimates of the coefficients depend on the relative variances of the shocks. If the relative variance of the oil market shock is large, for instance, the probability limit of $\widehat{\beta}_{0}$ is close to $\beta_{0}$. Changes in the relative variances of the shocks $\varepsilon_{g}$ and $\varepsilon_{o}$ will therefore cause changes in $\widehat{\beta}_{0}$. Rigobon (2003) built on that logic to derive the conditions under which heteroskedasticity is sufficient for identification of the system with no further restrictions.

The system $(2)-(3)$ can be rewritten in the reduced form:

$$
\begin{aligned}
\Delta \text { gas }_{t} & =\alpha_{g}+\sum_{i=1}^{k} \gamma_{i} \Delta g a s_{t-i}+\sum_{i=1}^{k} \beta_{i} \Delta o i l_{t-i}+\theta_{g} z_{t-1}+e_{g t} \\
\Delta o i l_{t} & =\alpha_{o}+\sum_{i=1}^{k} \delta_{i} \Delta g a s_{t-i}+\sum_{i=1}^{k} \omega_{i} \Delta o i l_{t-i}+\theta_{o} z_{t-1}+e_{o t}
\end{aligned}
$$

Define the reduced form residuals to $\mathrm{be}^{4}$

$$
\begin{aligned}
& e_{g t}=\varepsilon_{g t}+a \varepsilon_{o t} \\
& e_{o t}=b \varepsilon_{g t}+\varepsilon_{o t}
\end{aligned}
$$

\footnotetext{
${ }^{3}$ One might be tempted to use a non-US oil price as an instrument for WTI. Borenstein, et al (1997) used Brent crude as an instrument for West Texas Intermediate. That approach requires the assumption that oil prices are not determined in a global market, as all oil prices would be affected by shocks to the US gasoline market otherwise. Bachmeier and Griffin (2003) found that OLS and IV gave nearly identical parameter estimates.

${ }^{4}$ We have normalized the structural shocks so that $\varepsilon_{g t}$ has a one unit effect on $\Delta g a s_{t}$ and $\varepsilon_{o t}$ has a one unit effect on $\Delta$ oil .
} 
Under an assumption of homoskedasticity of $\varepsilon_{g}$ and $\varepsilon_{o}$, we have

$$
\begin{aligned}
\operatorname{var}\left(e_{g}\right) & =\operatorname{var}\left(\varepsilon_{g}\right)+a^{2} \operatorname{var}\left(\varepsilon_{o}\right) \\
\operatorname{var}\left(e_{o}\right) & =b^{2} \operatorname{var}\left(\varepsilon_{g}\right)+\operatorname{var}\left(\varepsilon_{o}\right) \\
\operatorname{cov}\left(e_{g}, e_{o}\right) & =b\left[\operatorname{var}\left(\varepsilon_{g}\right)\right]+a\left[\operatorname{var}\left(\varepsilon_{o}\right)\right]
\end{aligned}
$$

where $\operatorname{var}\left(e_{g}\right), \operatorname{var}\left(e_{o}\right)$, and $\operatorname{cov}\left(e_{g}, e_{o}\right)$ can be replaced with their sample counterparts. This is a system of three equations in four unknowns, so there is no way to estimate $a$ and $b$ without additional restrictions.

Now consider the case where there are two regimes for the variances of the structural shocks. Letting the superscript denote the regime, we have

$$
\begin{aligned}
\operatorname{var}\left(e_{g}^{1}\right) & =\operatorname{var}\left(\varepsilon_{g}^{1}\right)+a^{2} \operatorname{var}\left(\varepsilon_{o}^{1}\right) \\
\operatorname{var}\left(e_{o}^{1}\right) & =b^{2} \operatorname{var}\left(\varepsilon_{g}^{1}\right)+\operatorname{var}\left(\varepsilon_{o}^{1}\right) \\
\operatorname{cov}\left(e_{g}^{1}, e_{o}^{1}\right) & =b\left[\operatorname{var}\left(\varepsilon_{g}^{1}\right)\right]+a\left[\operatorname{var}\left(\varepsilon_{o}^{1}\right)\right] \\
\operatorname{var}\left(e_{g}^{2}\right) & =\operatorname{var}\left(\varepsilon_{g}^{2}\right)+a^{2} \operatorname{var}\left(\varepsilon_{o}^{2}\right) \\
\operatorname{var}\left(e_{o}^{2}\right) & =b^{2} \operatorname{var}\left(\varepsilon_{g}^{2}\right)+\operatorname{var}\left(\varepsilon_{o}^{2}\right) \\
\operatorname{cov}\left(e_{g}^{2}, e_{o}^{2}\right) & =b\left[\operatorname{var}\left(\varepsilon_{g}^{2}\right)\right]+a\left[\operatorname{var}\left(\varepsilon_{o}^{2}\right)\right]
\end{aligned}
$$

There are now six equations and six unknowns, $a, b, \operatorname{var}\left(\varepsilon_{g}^{1}\right), \operatorname{var}\left(\varepsilon_{o}^{1}\right), \operatorname{var}\left(\varepsilon_{g}^{2}\right)$, and $\operatorname{var}\left(\varepsilon_{o}^{2}\right)$. Under heteroskedasticity, there is not an identification problem, so no further assumptions are needed for estimation. The reduced form $(4)$ - (5) can be estimated by OLS, the covariance matrix of the reduced form residuals can be computed for both regimes, and the contemporaneous coefficients $a$ and $b$ and the variances of the structural shocks can be estimated by GMM. Inference is carried out using the fixed-design wild bootstrap of Goncalves and Kilian (2004) with the Rademacher distribution as the pick distribution (Godfrey (2009)).

The key question is how one goes about identifying regimes in which the relative variances of the US gasoline market and oil market shocks changed. We use the Gulf War period of August 1990 to February 1991 as regime 1 and all other observations as regime 2. The war period should have been a time when most of the shocks were originating in the world oil market rather than in local gasoline markets. Both the price of gasoline and the price of oil were affected during the war period, but that primarily reflected uncertainty about the supply of oil, not shocks to the US gasoline market. As the identification strategy delivers estimates of the variances of $\varepsilon_{g}$ and $\varepsilon_{o}$ in both regimes, we can formally verify that this choice of 
regimes for the heteroskedasticity is appropriate. ${ }^{5}$

\section{Results}

The estimated parameters can be found in Table 1. In brackets below the estimates of the coefficients $a$ and $b$ are p-values for tests of the null hypotheses $H_{0}: a=0$ and $H_{0}: b=0$. Bootstrap standard errors are reported in parenthesis below the estimated variances. As identification requires heteroskedasticity of the structural shocks, we also report the ratio of the estimated variances of the structural shocks. In brackets below the estimates are p-values for tests of the null hypotheses $H_{0}: \operatorname{var}\left(\varepsilon_{g}^{1}\right) / \operatorname{var}\left(\varepsilon_{g}^{2}\right) \leq 1$ and $H_{0}: \operatorname{var}\left(\varepsilon_{o}^{1}\right) / \operatorname{var}\left(\varepsilon_{o}^{2}\right) \leq 1$.

It is clear that the variances of the structural shocks were different in the two regimes. Specifically, consistent with expectations, the variance of the oil market shock was seven times larger in the war regime than at other times for the baseline (VEC) model. The bootstrap p-value for a test of the null hypothesis that $\operatorname{var}\left(\varepsilon_{o}^{1}\right)=\operatorname{var}\left(\varepsilon_{o}^{2}\right)$ is $0.00 .{ }^{6}$ As discussed above, identification depends on changes in the relative variances of the shocks through time, so there is no danger that the change in the variance of the gasoline market shock is too small. The large increase in the variance of the oil market shock during wartime is sufficient for identification.

Shocks to the price of oil, as expected, have a large and statistically significant positive same-day effect on the price of oil. On the other hand, we find no evidence of contemporaneous feedback from the US gasoline market to the price of West Texas Intermediate crude oil. The estimate of $b$ is economically and statistically insignificant. The sign is the opposite of what would be expected if gasoline demand shocks affected the price of oil within the impact period. These findings are robust across specifications.

This finding has important implications for empirical research on the relationship between gasoline and oil prices. It implies that the responses of the price of gasoline to oil price shocks can be computed based on recursively identified econometric models in which the innovation to the price of oil is ordered first. More generally, our analysis supports the common assumption that innovations in the price of oil may be viewed as predetermined with respect to the U.S. economy.

\footnotetext{
${ }^{5}$ It is not necessary to specify all the different heteroskedasticity regimes. Identification requires only that there are differences in the variances across the regimes we have selected (Rigobon (2003)).

${ }^{6}$ In none of the bootstrap replications was $\operatorname{var}\left(\varepsilon_{o}^{1}\right)<\operatorname{var}\left(\varepsilon_{o}^{2}\right)$.
} 
Table 1: Parameter Estimates

\begin{tabular}{|c|c|c|c|}
\hline Parameter & VEC & VAR (levels) & VAR (differences) \\
\hline \multirow[t]{2}{*}{$a$} & 0.69 & 0.85 & 0.69 \\
\hline & {$[0.00]$} & {$[0.00]$} & {$[0.00]$} \\
\hline \multirow[t]{2}{*}{$b$} & -0.04 & -0.05 & -0.03 \\
\hline & {$[1.00]$} & {$[1.00]$} & {$[1.00]$} \\
\hline \multirow[t]{2}{*}{$\operatorname{var}\left(\varepsilon_{g}^{1}\right)$} & 6.16 & 0.80 & 6.29 \\
\hline & $(0.21)$ & $(0.08)$ & $(0.17)$ \\
\hline \multirow[t]{2}{*}{$\operatorname{var}\left(\varepsilon_{o}^{1}\right)$} & 38.4 & 3.02 & 39.3 \\
\hline & $(0.09)$ & $(0.11)$ & $(0.96)$ \\
\hline \multirow[t]{2}{*}{$\operatorname{var}\left(\varepsilon_{g}^{2}\right)$} & 3.90 & 1.31 & 3.89 \\
\hline & $(0.01)$ & $(0.05)$ & $(0.07)$ \\
\hline \multirow[t]{2}{*}{$\operatorname{var}\left(\varepsilon_{o}^{2}\right)$} & 5.58 & 1.21 & 5.58 \\
\hline & $(0.03)$ & $(0.01)$ & $(0.02)$ \\
\hline \multirow[t]{2}{*}{$\operatorname{var}\left(\varepsilon_{g}^{1}\right) / \operatorname{var}\left(\varepsilon_{g}^{2}\right)$} & 1.59 & 0.63 & 1.62 \\
\hline & {$[0.00]$} & {$[1.00]$} & {$[0.00]$} \\
\hline \multirow[t]{2}{*}{$\operatorname{var}\left(\varepsilon_{o}^{1}\right) / \operatorname{var}\left(\varepsilon_{o}^{2}\right)$} & 6.88 & 2.51 & 7.04 \\
\hline & {$[0.00]$} & {$[0.00]$} & {$[0.00]$} \\
\hline
\end{tabular}




\section{References}

Bachmeier, Lance J. and James M. Griffin (2003), "New Evidence on Asymmetric Gasoline Price Responses," Review of Economics and Statistics (85), 3, 772-776.

Borenstein, Severin, A. Colin Cameron and Richard Gilbert (1997), "Do Gasoline Prices Respond Asymmetrically to Crude Oil Price Changes?" Quarterly Journal of Economics (112), 1, 305-339.

Geweke, John (2004), "Issues in the 'Rockets and Feathers' Gasoline Price Literature," Report to Federal Trade Commission.

Godby, Robert, Anastasia M. Lintner, Thanasis Stengos, and Bo Wandschneider (2000), "Testing for Asymmetric Pricing in the Canadian Retail Gasoline Market," Energy Economics (22), 3, 349-368.

Godfrey, Leslie (2009), Bootstrap Tests for Regression Models, New York: Palgrave Macmillan.

Goncalves, S., and L. Kilian (2004), "Bootstrapping Autoregressions in the Presence of Conditional Heteroskedasticity of Unknown Form," Journal of Econometrics, 123, 89-120.

Hamilton, James D. (1994), Time Series Analysis, Princeton, NJ: Princeton University Press.

Hamilton, James D. (2009), "Causes and Consequences of the Oil Shock of 2007-08," Brookings Papers on Economic Activity, Spring, 215-259.

Kilian, Lutz (2009), "Not All Oil Price Shocks Are Alike: Disentangling Demand and Supply Shocks in the Crude Oil Market," American Economic Review (99), 1053-1069.

Kilian, L. (2010), "Explaining Fluctuations in U.S. Gasoline Prices: A Joint Model of the Global Crude Oil Market and the U.S. Retail Gasoline Market," Energy Journal, 31, 87-104.

Kilian, Lutz, R. Alquist and R.J. Vigfusson (2012), "Forecasting the Price of Oil," Handbook of Economic Forecasting, G. Elliott and A. Timmerman (eds.), Camberley, UK: Edward Elgar.

Kilian, L., and D.P. Murphy (2012), "Why Agnostic Sign Restrictions Are Not Enough: Understanding the Dynamics of Oil Market VAR Models," Journal of the European Economic Association, 10, 1166-1188.

Kilian, L., and D.P. Murphy (2013), "The Role of Inventories and Speculative Trading in the Global Market for Crude Oil," Journal of Applied Econometrics, forthcoming.

Kilian, L., and C. Vega (2011), "Do Energy Prices Respond to U.S. Macroeconomic News? A Test of the Hypothesis of Predetermined Energy Prices," Review of Economics and Statistics, 93, 660-671.

Kilian, L., and R.J. Vigfusson (2011), "Are the Responses of the U.S. Economy Asymmetric in Energy Price Increases and Decreases?" Quantitative Economics, 2, 419-453.

Rigobon, Roberto (2003), "Identification Through Heteroskedasticity," Review of Economics and Statistics (85), 4, 777-792.

Verlinda, Jeremy A. (2008), "Do Rockets Rise Faster and Feathers Fall Slower in an Atmostphere of 
Local Market Power? Evidence From the Retail Gasoline Market," Journal of Industrial Economics (56), 3, 581-612. 